\title{
Wissenschaft mit Wetterwechsel
}

Die alljährliche Fortbildungswoche des Freien Verbandes Deutscher Zahnärzte (FVDZ) auf Usedom lockt traditionell viele Teilnehmer an. Denn die Insel am äußersten nordöstlichen Zipfel Deutschlands verspricht neben vielfältigen Seminaren im Juni meist auch volle Sonne. In diesem Jahr allerdings mussten die Fortbildungswilligen sich zunächst einmal mit einem vollen Seminarkalender begnügen - die Sonne kam erst später.

Der Zahnärzte-Sommerkongress ist bekannt für sein abwechslungsreiches Programm: Ob moderne Endodontie, Therapie bei Senioren, Kieferorthopädie, Parodontaltherapie, minimalinvasive Eingriffe, Füllungstherapie oder moderne Methoden der Anästhesie - der Themenmix aus zahnmedizinisch-wissenschaftlichen Angeboten bis hin zu praxisökonomischen oder rechtlichen Themen und praktischen Hands-on-Seminaren bietet den Teilnehmern ein einzigartiges Fortbildungsspektrum. Maßgeschneidert kann dort jeder sein Programm für sein Fachgebiet und seine Praxis zusammenstellen. „Das Konzept scheint so aufzugehen", sagte Kongressleiter Dr. Peter Bührens nach dem Kongress, der in diesem Jahr eine Rekordzahl an Seminar- buchungen verzeichnete. Die Zahl der Kongressbesucher variiert von Jahr zu Jahr leicht bei etwas mehr als 700 Teilnehmern, aber die Frequenz der einzeln zu buchenden Seminare ist seit dem vergangenen Jahr noch einmal deutlich angestiegen. „Da treffen wir anscheinend den richtigen Ton“, zeigt sich Bührens mit den jüngsten Veränderungen des Kongressprogramms zufrieden. „Das ist eine Woche lang sehr kompakte und intensive Fortbildung“, sagt der Kongressleiter, „allerdings gepaart mit dem besonderen Flair der Kaiserbäder auf Usedom." Dieses konnten die Kongressteilnehmer in diesem Jahr etwa in der Mitte der Fortbildungswoche dann auch bei schönstem Inselwetter genießen.
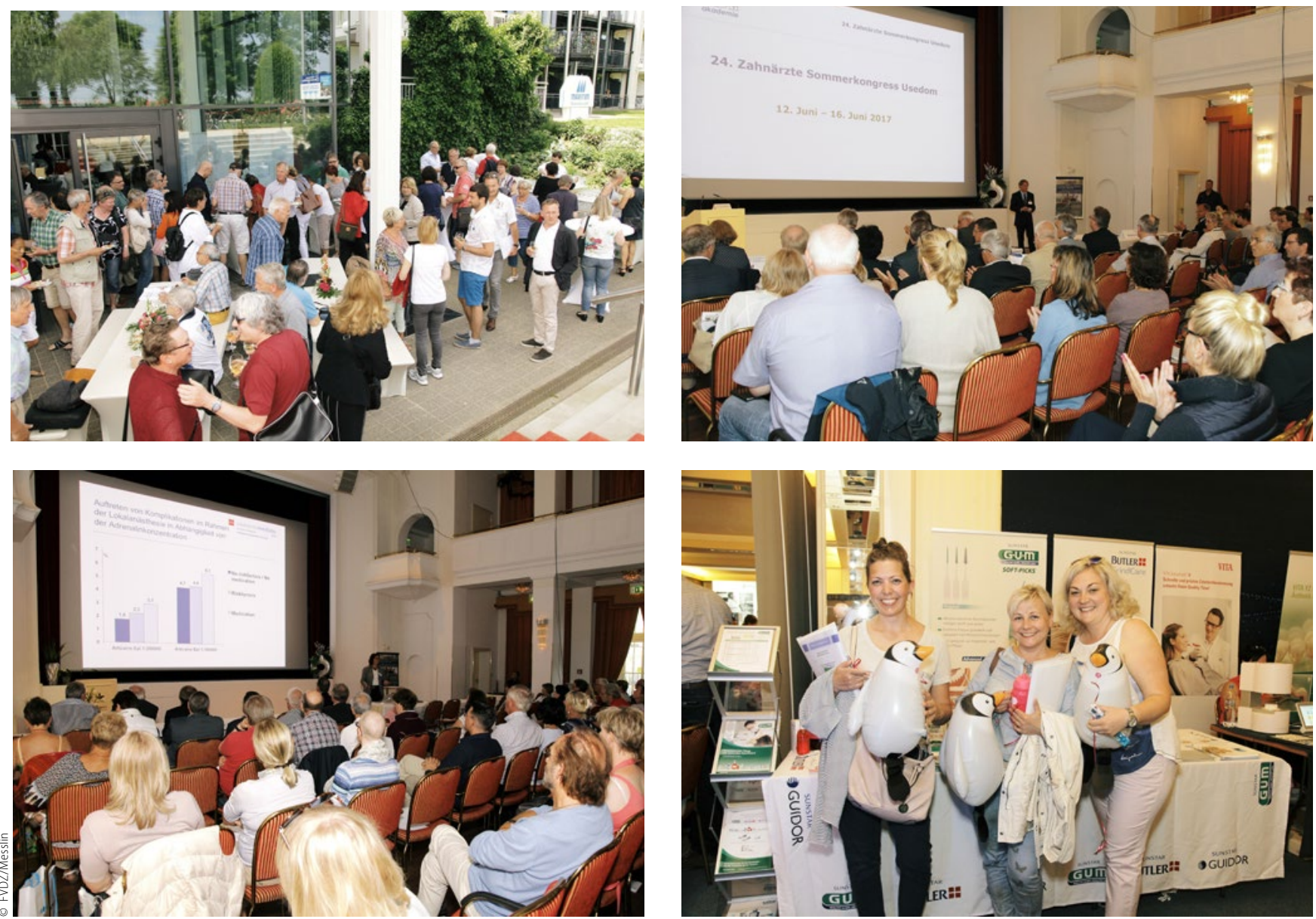

Kongressleiter Dr. Peter Bührens kann vor vollem Haus im Kaiserbädersaal in Heringsdorf den 24. Zahnärzte-Sommerkongress eröffnen. Drinnen wie draußen: Es ist viel los, wenn sich mehr als 700 Zahnärzte zum fachlichen Austausch treffen. 